\title{
Concurso Inovação completa sua 15a Edição premiando 10 iniciativas
}

\author{
Além de anunciar os vencedores de 2010, \\ cerimônia de premiação marcou lançamento da \\ publicação sobre os melhores colocados e do \\ concurso de 2011
}

"A sua pequena mudança pode ser uma grande inovação". As iniciativas inscritas anualmente no Concurso Inovação refletem o slogan do prêmio. Graças ao trabalho de uma das equipes ganhadoras da $15^{a}$ edição do Inovação - do Ministério da Saúde -, famílias de diferentes regiões do país têm atendimento personalizado de saúde, promovido por um agente que se foca na prevenção e manutenção da saúde da comunidade. Em outra frente, o acompanhamento e a orientação da equipe do Banco do Nordeste garantiu a pequenos produtores rurais créditos eficientes com orientação personalizada, que levaram ao crescimento de suas produções.

Outra agraciada pelo prêmio, uma iniciativa do Ministério do Desenvolvimento Social, sistematiza um conjunto de ações intersetoriais para o acompanhamento de famílias em situação de risco social. Foi com o intuito de incentivar tal ciclo de melhoria dos serviços públicos que o Concurso Inovação foi criado, há 15

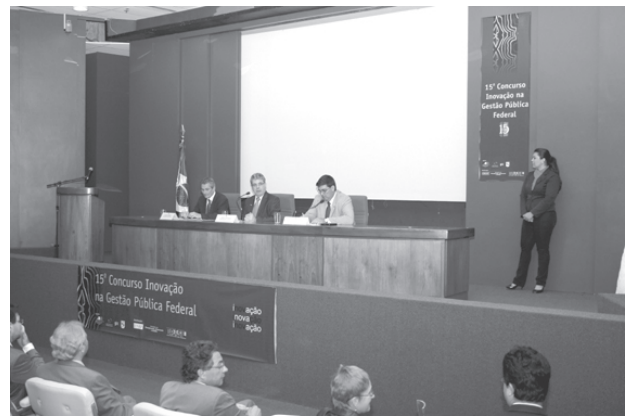

As equipes premiadas fizeram breves apresentações de suas iniciativas

anos. Desde então, foram premiadas 311 equipes de um total de 1.426 experiências avaliadas. Uma das principais finalidades do Concurso é o reconhecimento e a valorização das equipes inovadoras, fundamentais não só para a concepção das iniciativas, como também para sua sustentabilidade.

"O Concurso Inovação privilegia a dimensão da gestão, como reformulação de processos ou programas que já existiam na organização ou adoção e adaptações 
de inovações provenientes de outras organizações para gerar inovação", explicou o presidente da ENAP, Paulo Carvalho, na cerimônia de premiação dos dez vencedores na $15^{\text {a }}$ edição, promovida em 25 de abril deste ano.

$\mathrm{Na}$ mesma ocasião, a ministra do Planejamento, Orçamento e Gestão, Miriam Belchior, gravou um vídeo para os presentes. "O Concurso Inovação traz importante contribuição ao identificar exemplos e padrões para a modernização de gestão que resultam em melhores serviços e mais efetividade nas políticas públicas", afirmou. Também estiveram presentes o secretário executivo adjunto do Ministério do Planejamento, Valter Correia, e o presidente do Instituto Nacional do Seguro Social (INSS), Mauro Hauschild. A solenidade também marcou os lançamentos do livro contendo o relato das práticas inovadoras premiadas em 2010 e da $16^{a}$ edição do Concurso Inovação.

Para a coordenadora-geral de Pesquisa da ENAP (área que gerencia o Concurso), Elisabete Ferrarezi, a as motivações das iniciativas premiadas no Concurso Inovação têm em comum a necessidade de resolver um problema permanente das instituições, como a entrega dos serviços a que se propunham. "As equipes de servidores preocupam-se em alcançar o cidadão e melhorar sua vida por meio dessas inovações. Iniciativas como 'A Estratégia de Saúde da Família', 'Gestão de Condicionalidades' e 'Acompanhamento das Famílias do Programa Bolsa Família' são exemplos de práticas inovadoras com foco no usuário, na qualidade do serviço prestado e que estão em sintonia com a agenda do governo. Essas inovações no serviço público indicam a preocupação do poder Executivo Federal em aumentar o acesso à cidadania e isso foi bem representado na $15^{\text {a }}$ edição do Concurso Inovação pelas práticas 'Aposentadoria em até 30 minutos', do INSS, 'Programa Banda Larga nas Escolas', do Ministério da Educação, e 'Agenda Social de Registro Civil de Nascimento e Documentação Básica', da Secretaria de Direitos Humanos da Presidência da República”, disse.

Segundo Ferrarezi, o impacto que essas experiências causam na população vem muitas vezes de ideias menos complexas e soluções simplificadas, como as centrais de serviços onde o cidadão resolve toda sua vida em um lugar só, ganhando tempo. "O próprio servidor torna-se motivado ao ver o resultado alcançado com a melhoria dos seus serviços prestados à sociedade", ressaltou.

Entre os prêmios dessa edição, houve visitas técnicas internacionais à França e à Alemanha, cursos no Japão e bolsas para cursos da ENAP - entre eles, o de Especialização em Gestão Pública. Os vencedores também receberam certificado, assinatura da Revista do Serviço Público, Selo Inovação e publicação dos relatos no Banco de Soluções disponibilizado no hot site do prêmio e em livro. Promovido pela ENAP, em parceria com o Ministério do Planejamento, o $15^{\circ}$ Inovação contou com o apoio da Embaixada da França, da Agência de Cooperação Internacional do Japão (Jica) e da Agência Alemã de Cooperação Internacional (GIZ).

\section{5 anos de Inovação}

Desde sua criação, o Concurso teve focos diferenciados, que acompanharam a evolução da administração pública brasileira, mantendo aspectos da gestão pública que se consolidaram, como estabelecimento de parcerias, melhoria nos processos de trabalho, bem como preocupação com recursos, resultados, 
atendimento ao cidadão e gestão de informações.

“Ter sido vencedora da $15^{a}$ edição do Prêmio de Inovação da ENAP deu visibilidade e trouxe o merecido reconhecimento ao trabalho realizado por um exército de trabalhadores da Saúde em mais de 32 mil equipes de Saúde da Família, distribuídos atualmente em 5.282 municípios brasileiros. Trabalho cotidiano e silencioso que permitiu que a Estratégia Saúde da Família no Brasil fosse responsável pelas mudanças nos indicadores de saúde, melhorando o acesso, coordenando os cuidados de saúde de forma mais integral e continua, promovendo a inclusão social e a cidadania da população sob sua responsabilidade. Fazendo também o [Sistema Único de Saúde] SUS dar cada vez mais certo no nosso país", detalhou a médica Elisabeth Wartchow, coordenadora de
Acompanhamento e Avaliação do Departamento de Atenção Básica do Ministério da Saúde e responsável pelo programa Saúde da Família.

Após 15 anos, o Concurso tem cumprido seus objetivos de incentivar a implementação de iniciativas inovadoras no governo federal e disseminar as soluções, para que elas sirvam de inspiração, além de valorizar os servidores públicos que atuem de forma criativa e proativa. "Este prêmio representa uma oportunidade de apresentar à Administração Pública e à sociedade a mudança de cultura, a quebra de paradigmas e o atendimento mais resolutivo com foco para o cidadão como melhoria da qualidade do serviço prestado pelo INSS", Míriam Fernandes, da iniciativa Aposentadoria em até 30 Minutos. Para atingir esses resultados, o método de seleção e

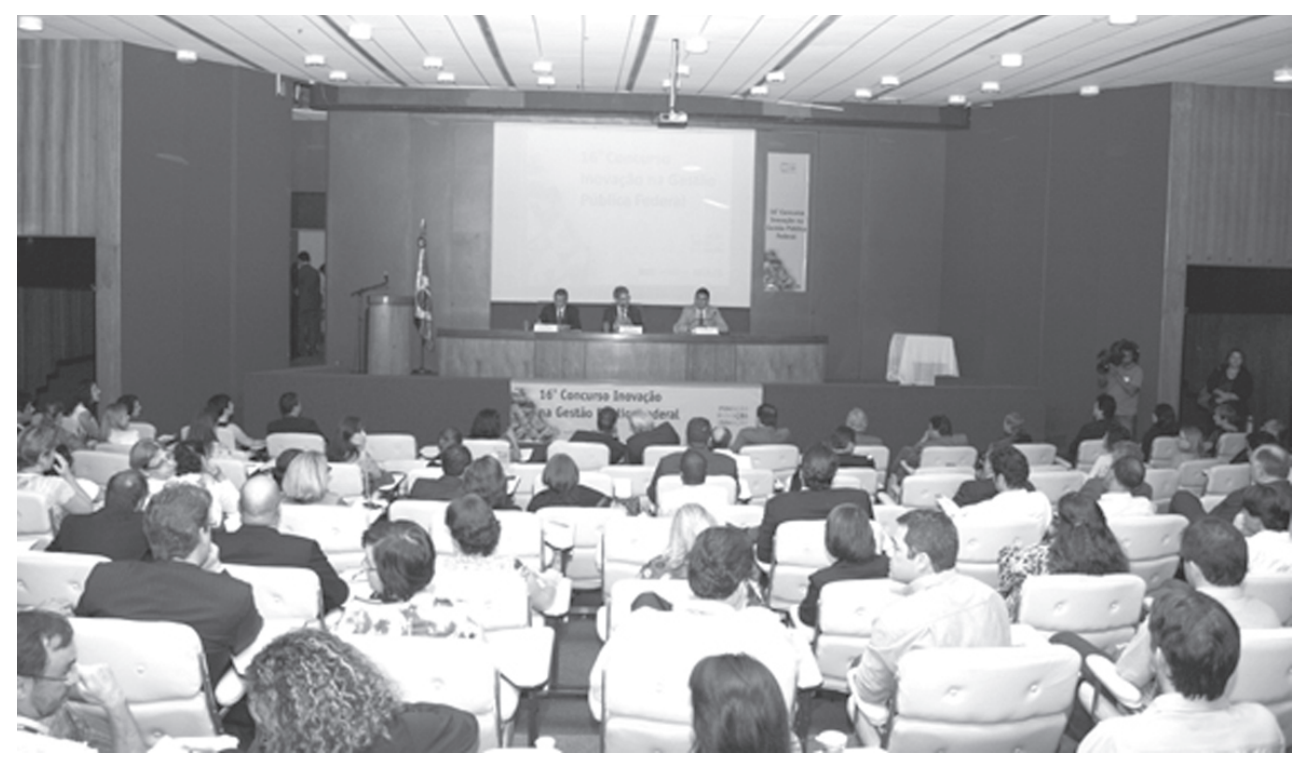

O $15^{\circ}$ Concurso Inovação na Gestão Pública Federal obteve 117 inscrições válidas, de um total de 139 inscritas - ou seja, $85 \%$ do total 
avaliação das ações inscritas é minucioso, abarcando diversas etapas, que incluem participação de um comitê julgador diversificado, que avalia cada iniciativa a partir de critérios específicos, e visitas técnicas (realizada por um comitê técnico) para observação in loco do funcionamento de cada prática selecionada.

Tal procedimento se torna incentivador para inscrições no Concurso, como explica Beatriz Garrido, Coordenadora-geral de Promoção do Registro Civil de Nascimento da Secretaria de Direitos Humanos da Presidência da República e responsável pela iniciativa Agenda Social Registro Civil de Nascimento e Documentação Básica: comitês gestores da agenda social: "É sempre muito importante o reconhecimento do trabalho feito em equipe e articulado entre tantas e tão diversas instituições públicas e privadas. A lisura e seriedade na condução do prêmio, a partir da análise minuciosa e técnica das atividades desenvolvidas pelas instituições, bem como dos resultados efetivamente obtidos, nos motivou ainda mais. A gestão das políticas públicas voltadas à promoção dos direitos humanos não é tarefa simples, e ser premiado como modelo de inovação nos dá a certeza de estarmos no caminho certo na luta pela garantia do direito humano ao nome e ao sobrenome".

\section{As vencedoras da $15^{\mathrm{a}}$ Edição}

Das 10 premiadas nessa edição, seis pertencem à administração direta (ministérios e Presidência da República), duas a autarquias, uma à fundação e uma pertencente à sociedade de economia mista. Elas possuem média de seis anos de duração, tendo a mais antiga 16 anos de existência e a mais nova, um ano. As 10 estão divididas em quatro áreas temáticas: arranjos institucionais para coordenação e/ ou implementação de políticas públicas; atendimento ao cidadão; gestão da informação; e melhoria dos processos de trabalho. São elas:

\section{Saúde da família, do Ministério da Saúde}

Coordenada pelo Ministério da Saúde e classificada em $1^{\circ}$ lugar, a iniciativa "Saúde da Família" é uma estratégia de reorientação do modelo assistencial com a implantação de equipes multiprofissionais em unidades básicas de saúde. Essas são responsáveis pelo acompanhamento de um número definido de famílias, localizadas em área geográfica delimitada. As equipes atuam com ações de promoção da saúde, prevenção, recuperação, reabilitação de doenças e agravos mais frequentes, e na manutenção da saúde da comunidade. A responsabilidade pelo acompanhamento das famílias impõe aos grupos de trabalhadores do programa a necessidade de ultrapassar os limites tradicionais de atenção básica no Brasil, sobretudo no contexto do Sistema Único de Saúde (SUS). A implantação da estratégia de Saúde da Família tem demonstrado significativa melhora nos indicadores de saúde do país, em especial naqueles que

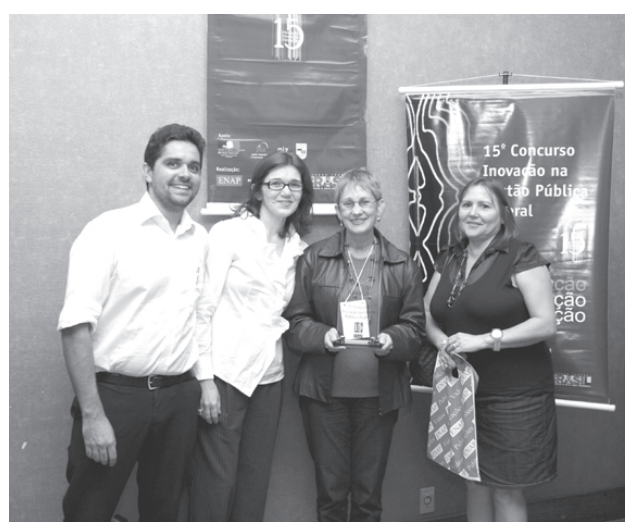

Equipe responsável pela "Estratégia da Saúde da Família” 
dizem respeito à ampliação do acesso a esse serviço. Houve também efetiva redução das iniquidades, com o projeto cumprindo seu papel de porta de entrada do SUS.

Entre as características que fazem da iniciativa uma inovação, está o fato de as equipes multidisciplinares serem responsáveis por territórios geográficos - eles devem reconhecer adequadamente problemas de todos os tipos, sejam eles de ordem funcional, orgânica ou social. A presença singular dos agentes comunitários de saúde e a inclusão da saúde bucal no sistema público de saúde também são considerados aspectos inovadores que diferenciam o modelo brasileiro da Saúde da Família dos modelos de saúde de outros países.

\section{Agroamigo, do Banco do Nordeste do Brasil}

No Nordeste, a agricultura familiar representa 82,9\% da ocupação de mão de obra no campo. Considerando o fato, o Banco do Nordeste desenvolveu o Agroamigo, uma inovação em metodologia de concessão de crédito para os agricultores familiares de baixa renda. Classificado em $2^{\circ}$ lugar nessa edição do Inovação, o projeto possibilita aos agricultores serem atendidos em suas próprias comunidades, diminuindo os deslocamentos para a agência, além de receberem acompanhamento e orientação de um especialista em atividades rurais. A iniciativa promove a educação financeira, esclarecendo questões sobre endividamento, planejamento financeiro, poupança, melhores formas de alocar recursos, uso correto do crédito e a importância do retorno do recurso para o governo federal. O Agroamigo é o maior programa de microfinanças rural do Brasil, tendo recebido reconhecimento nacional e internacional. Por conceder crédito de forma gradual e sequencial, tem promovido o desenvolvimento sustentável das atividades financiadas e reduziu a inadimplência de 63,94\% para 4,68\%.

Diversas premissas fazem do Agroamigo uma prática inovadora. A parceria na operacionalização permitiu a melhoria do atendimento em escala, maior agilidade e flexibilidade do processo de concessão de crédito. Os clientes recebem acompanhamento e orientação permanente de um assessor especializado, conferindo segurança às atividades financeiras. A aplicação de metodologia é monitorada permanentemente e, assim, mantém-se a qualidade do programa. O acesso é amplo e, por meio do assessor, é possível disponibilizar atendimento nos lugares mais longínquos e ao público mais necessitado. O modelo de gestão, que conta com compartilhamento entre instituições e controles rígidos de custos e inadimplência, também é um dos destaques do programa.

Gestão de condicionalidades e acompanhamento das famílias do Programa Bolsa família, do Ministério do Desenvolvimento Social e Combate à Fome

A experiência, que tirou a $3^{a}$ colocação, consiste em um conjunto de iniciativas, ações e procedimentos de caráter intersetorial e intergovernamental para o acompanhamento integral, nominal e massivo de famílias em situação de vulnerabilidade ou risco social. Atualmente, cerca de 6,5 milhões de famílias são acompanhadas em relação à agenda da saúde, e 14 milhões de crianças e adolescentes têm informações sobre sua frequência escolar registradas. Das famílias acompanhadas por meio da agende de saúde, 98,3\% tiveram cumprimento integral no último período. $\mathrm{Na}$ educação, o percentual foi 
de $97,3 \%$ das crianças de 6 a 15 anos com frequência regular nas escolas. As famílias em descumprimento são prioritariamente incluídas no acompanhamento realizado pela rede socioassistencial. Tais ações têm base na institucionalização de instâncias e processos de intensa articulação governamental, envolvendo as áreas de saúde, educação e assistência social em todos os estados e municípios do país.

A ação pode ser considerada uma inovação por sua extensa cobertura e modelo de execução descentralizado e intersetorial. Possibilita, assim, integração entre políticas sociais com foco nas famílias mais vulneráveis. Sua articulação se torna sólida graças aos compromissos assumidos, aos incentivos estabelecidos e também à significativa contribuição para o alcance dos objetivos específicos de todos os parceiros envolvidos. Com melhoras no atendimento ao cidadão e na obtenção de informações que apoiam a tomada de decisão, permite aperfeiçoar o uso de recursos financeiro, humano e de capital ao reduzir custos.

Programa Banda Larga nas Escolas, do Ministério da Educação

O "Banda Larga nas Escolas" tem por objetivo a inclusão das tecnologias de informação e comunicação (TICs) na realidade das escolas públicas urbanas nacionais, sem ônus para estados e municípios, com duração dos serviços até 2025. Para tanto, foi adotado um modelo de parceria público-privada com reflexo direto na condução e na duração do programa. Assim, ultrapassa as ações de um governo para ser reconhecido como ação de Estado por mais de 20 anos e perspectiva para perdurar como obrigação nas futuras concessões da exploração de serviços de telefonia e transporte multimídia no país.

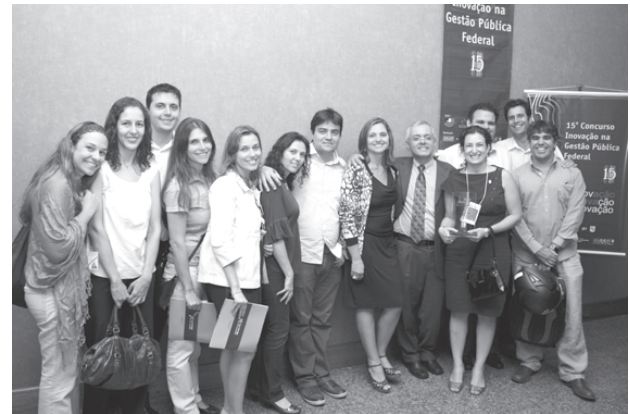

Equipe responsável pela Gestão de condicionalidades e acompanhamento das famílias do Programa Bolsa Família

Até o segundo trimestre de 2010, estavam conectadas 47.204 escolas, o que corresponde a $84 \%$ do compromisso inicial de 56 mil. Esse número de conexões beneficia aproximadamente 30 milhões de alunos da rede pública.

A principal inovação da experiência, que ficou em $4^{\circ}$ lugar, está no fato de que, no campo social, a troca de obrigação atingiu de maneira rápida e eficaz a população, criando oportunidades sociais ímpares que até pouco tempo não possuía sequer acesso à telefonia fixa. As possibilidades de ascensão social e educacional, que o programa proporciona à população brasileira que frequenta e depende da educação pública, somente poderão ser mensuradas dentro de alguns anos. Contudo, o programa já aponta para a socialização da informação e principalmente para a formação de cidadãos com acesso desde o início do processo de alfabetização aos instrumentos de tecnologia mais atuais de que a sociedade dispõe.

Portal de Periódicos da Coordenação de Aperfeicoamento de Pessoal de Nivel Superior (Capes)

O Portal de Periódicos da Capes disponibiliza às instituições de ensino superior e de pesquisa conteúdo atualizado e de alta qualidade. Permite consultas e acesso aos textos completos de artigos 
publicados em 23.925 revistas internacionais, nacionais e estrangeiras, e a mais de 124 bases de dados com resumos de documentos em todas as áreas do conhecimento. Classificada em $5^{\circ}$ lugar, a iniciativa tem como finalidade oferecer às universidades, institutos de pesquisa e organizações governamentais, não governamentais e particulares - onde se desenvolve a pósgraduação e a pesquisa do país - informação científica necessária à formação de recursos humanos de alto nível e desenvolvimento do conhecimento, tecnologia e inovação. $\mathrm{O}$ acesso à biblioteca eletrônica se dá via internet, por meio do site www.periodicos.capes.gov.br, de forma gratuita às organizações autorizadas. Em 2009, foram baixados mais de 65 milhões de documentos, entre textos completos e resumos.

O Portal de Periódicos pode ser considerado uma iniciativa inovadora porque a Capes realizou expressivo investimento na manutenção de coleções atualizadas tanto de textos completos quanto de outros tipos de materiais como bases de resumos, normas técnicas, patentes, material de referência e audiovisual. Em 2009, foi alcançada e ultrapassada a meta estipulada pela presidência da Capes de assinar 15 mil títulos de periódicos até o ano de 2010. Em decorrência disso, houve significativo incremento no número de títulos de texto completo, devendo-se considerar não somente a quantidade, mas também a qualidade das publicações assinadas.

Agenda Social Registro Civil de Nascimento e Documentação Básica: comitês gestores da agenda social, da Secretaria de Direitos Humanos da Presidência da República (SDH/PR)

Trata-se de uma iniciativa de gestão para implementação da Agenda Social Registro Civil de Nascimento e Documentação
Básica, envolvendo uma rede de órgãos e instituições de diversos poderes da República nos três níveis administrativos do Estado brasileiro, bem como instituições da sociedade civil e organismos internacionais, a partir da atuação de comitês gestores em nível central e descentralizados. A agenda, que conquistou a $6^{a}$ colocação, possibilitou intervir na formação de uma cultura de inclusão a partir da documentação civil, com base na realização das campanhas em nível nacional. Um dos resultados da implementação da agenda é a queda do índice de subregistro de nascidos vivos, que era de $20,9 \%$ em 2002, e passou para 12,2\% em 2007.

A inovação do projeto reside na realização de um trabalho integrado, envolvendo organizações de diversos poderes da República nos três níveis administrativos do Estado, da sociedade civil e instituições internacionais para tratar dessa temática (até então relegada ao esquecimento). Com isso, foi se possível monitorar e reorientar a ação desenvolvida sempre que necessário, partindo de um projeto artesanal de governo para conquistar prioridade governamental como política pública nacional.

O Sistema de Controle Logístico de Medicamentos Antirretrovirais (Siclom), do Ministério da Saúde (MS)

O Sistema de Controle Logístico de Medicamentos Antirretrovirais (Siclom) é uma ferramenta criada com o objetivo de gerenciamento logístico dos medicamentos antirretrovirais (ARV) e de aprimoramento da qualificação da dispensação. Ele permite que o departamento de DST, Aids e Hepatites Virais e as secretarias estaduais e municipais de saúde mantenham-se atualizados em relação ao fornecimento e dispensação de medicamentos aos pacientes conforme as recomendações existentes no Consenso Terapêutico Brasileiro. O 
projeto, classificado em $7^{\circ}$ lugar, possibilita também o controle dos estoques de cada medicamento nas várias regiões do país. As informações de consumo e estoques são fundamentais para que o adequado suprimento aos estados ocorra, evitando, assim, a ruptura dos estoques locais e o prejuízo no atendimento aos pacientes. Atualmente, utilizam o sistema 670 unidades dispensadoras de medicamentos, distribuídas em todo o Brasil; 27 coordenações estaduais de DST/Aids; 61 almoxarifados; e 936 maternidades.

A contrário de outras ferramentas existentes no MS, o Siclom inova ao atender o planejamento das necessidades de insumos estratégicos, fundamentais para as ações de controle e combate às morbidades. Considerando a descentralização das ações de saúde estabelecidas pelo SUS, a autonomia dada aos estados pela Constituição e a implantação de uma ferramenta de gestão primordialmente federal, em que os estados fazem adesão, a ação atende às necessidades de ambos os entes federados.

\section{Educacenso, do Instituto Nacional de Estudos e Pesquisas Educacionais Anísio Teixeira (Inep).}

O Educacenso é um sistema eletrônico de coleta de informações educacionais composto por um aplicativo web, que permite a coleta, migração e alteração de dados educacionais das escolas em todo o território nacional e por um banco de dados relacional, que armazena de forma sistemática todas as informações. A ferramenta, que tirou o $8^{\circ}$ lugar, consiste em um banco de dados único, de base nacional, alimentado por dados e informações que vêm diretamente das escolas, pela internet. Constituise no mais completo cadastro de escolas, alunos e docentes do país. Sua construção com informações individualizadas amplia as possibilidades de comunicação com outras bases de dados do governo federal. O novo desenho metodológico e a utilização de recursos de tecnologia da informação permitiram ampliar a precisão e a fidedignidade dos dados do Censo Escolar, o que possibilita realização de ajustes na política educacional e maior efetividade do gasto público com a educação básica.

Pode-se dizer que a iniciativa é inovadora porque introduz um processo de responsabilização do informante e dos gestores educacionais, que são identificados e podem ser contatados a qualquer momento. O programa também trouxe ganho de qualidade no processo, com a diminuição de redundâncias e erros em razão da simplificação de formulários e da suspensão de etapas. Além disso, destacamse a facilidade de obtenção e o cruzamento de informações bem como a pesquisa e correção de informações inconsistentes.

\section{Aposentadoria em até 30 minutos, do Instituto Nacional do Seguro Social (INSS)}

A procura pela qualidade e resolutividade do reconhecimento do direito previdenciário em menor tempo é prioridade do INSS. Da forma implementada anteriormente, o serviço (classificado em $9^{\circ}$ lugar) não atendia à necessidade da sociedade, pois havia demora significativa na resolução dos processos de benefícios. Isso porque cabia ao segurado a apresentação e comprovação da documentação necessária ao direito. Após vários debates promovidos pelo Instituto e a mudança no fluxo do reconhecimento do direito, o instituto pôde garantir que maior número de segurados tenha acesso ao reconhecimento em até 30 minutos, considerando a inversão do ônus da prova e, assim, dispensando a apresentação de documentos pelo segurado. A internalização do novo conceito e da fixação de metas garantiu a redução no 
tempo médio de atendimento do cidadão.

Uma das principais inovações diz respeito exatamente à resolutividade e ao reconhecimento do direito em até 30 minutos, demonstrando a mudança de cultura, a quebra de paradigmas e a reversão da imagem que a sociedade tinha do INSS. Ao longo do tempo, o instituto enfrentou o descrédito, a falta de apoio e o risco da própria existência. A redução da burocracia associada à inversão do ônus da prova e ao acesso aos direitos previdenciários, além da manutenção de cadastros atualizados, garante melhor serviço à sociedade.

Pensando o Direito, do Ministério da Justiça (MJ)

O projeto Pensando o Direito tem por objetivo qualificar o trabalho jurídico da Secretaria de Assuntos Legislativos do Ministério da Justiça, abrindo espaço para a absorção da produção acadêmica de ponta, bem como fortalecendo seu trabalho de elaboração normativa. O projeto, que ficou na $10^{a}$ colocação, é realizado pela Secretaria de Assuntos Legislativos do Ministério da Justiça (SAL/MJ), por meio de acordo de cooperação técnica com o Programa das Nações Unidas para o Desenvolvimento (PNUD) e implementado por meio de cartas-acordo com instituições de ensino e pesquisa de todo o país. Foram firmadas parcerias, por meio de seis seleções públicas, com instituições acadêmicas de ensino e pesquisa em 42 áreas temáticas previamente definidas pela SAL/MJ. O objetivo é o fomento à pesquisa de caráter empírico e multidisciplinar de assuntos jurídicos pouco debatidos na academia, mas em discussão na sociedade. De 2007 a 2010, foram apresentadas 265 propostas de projetos de pesquisa por 152 instituições e, dessas, 43 foram aprovadas.

A iniciativa inova de maneira radical ao democratizar o processo de elaboração normativa, em especial no Poder Executivo, abrindo as portas dos gabinetes e aproximando a academia do processo legislativo brasileiro. Com uma iniciativa simples e de baixo custo global (em que pese o projeto ser hoje, reconhecidamente, o maior financiador de pesquisas jurídicas do país), obteve resultados concretos em pouco tempo: imediatamente qualificou o trabalho da Secretaria e os debates legislativos travados no Congresso Nacional; mediatamente, fomentou a pesquisa jurídica empírica no país e resgatou a importância do processo legislativo para a academia.

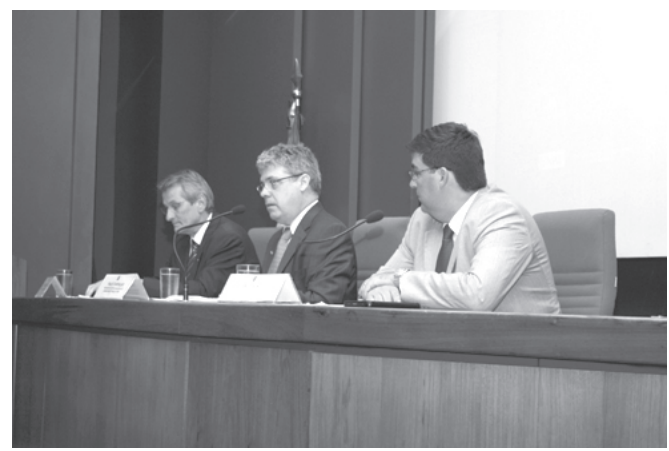

Secretário executivo adjunto do MP, Valter Correia, e os presidentes da ENAP, Paulo Carvalho, e do INSS, Mauro Hauschild 


\section{inovação \\ nova \\ inovação}

\section{Inovando pelo $16^{\circ}$ ano}

Iniciativa da ENAP em parceria com o MP, a $16^{a}$ edição do Inovação já está em andamento e premiará as 10 melhores práticas inovadoras com visitas técnicas internacionais à França, à Alemanha (ou a um país que tenha cooperação técnica com a Alemanha), à Noruega e a países da África e América do Sul. A solenidade de premiação está prevista para março de 2012.

O concurso procura identificar, premiar e disseminar iniciativas inovadoras de gestão pública. Busca ainda valorizar o trabalho de servidores públicos que, com seus esforços, transformam ideias em ações inovadoras, beneficiando cidadãos. Podem participar equipes de servidores de órgãos e entidades do Poder Executivo federal e de organizações sociais, que atuem de forma criativa em processos de mudança nas práticas de gestão.

São consideradas inovações mudanças em práticas anteriores, por meio da incorporação de novos elementos da gestão pública ou de uma nova combinação dos mecanismos existentes, que produzam resultados positivos para o serviço público e para a sociedade.

Acesse o site do Concurso Inovação: http://inovacao.enap.gov.br/ 